\title{
The dynamics of male-male competition in Cardiocondyla obscurior ants
}

\author{
Sylvia Cremer ${ }^{1,2^{*}}$, Masaki Suefuji ${ }^{1}$, Alexandra Schrempf ${ }^{1}$ and Jürgen Heinze ${ }^{1}$
}

\begin{abstract}
Background: The outcome of male-male competition can be predicted from the relative fighting qualities of the opponents, which often depend on their age. In insects, freshly emerged and still sexually inactive males are morphologically indistinct from older, sexually active males. These young inactive males may thus be easy targets for older males if they cannot conceal themselves from their attacks. The ant Cardiocondyla obscurior is characterised by lethal fighting between wingless ("ergatoid") males. Here, we analyse for how long young males are defenceless after eclosion, and how early adult males can detect the presence of rival males.

Results: We found that old ergatoid males consistently won fights against ergatoid males younger than two days. Old males did not differentiate between different types of unpigmented pupae several days before emergence, but had more frequent contact to ready-to-eclose pupae of female sexuals and winged males than of workers and ergatoid males. In rare cases, old ergatoid males displayed alleviated biting of pigmented ergatoid male pupae shortly before adult eclosion, as well as copulation attempts to dark pupae of female sexuals and winged males. Ergatoid male behaviour may be promoted by a closer similarity of the chemical profile of ready-to-eclose pupae to the profile of adults than that of young pupae several days prior to emergence.

Conclusion: Young ergatoid males of C. obscurior would benefit greatly by hiding their identity from older, resident males, as they are highly vulnerable during the first two days of their adult lives. In contrast to the winged males of the same species, which are able to prevent ergatoid male attacks by chemical female mimicry, young ergatoids do not seem to be able to produce a protective chemical profile. Conflicts in male-male competition between ergatoid males of different age thus seem to be resolved in favour of the older males. This might represent selection at the colony level rather than the individual level.
\end{abstract}

Keywords: Sexual selection, Male-male competition, Fighting, Cuticular hydrocarbons, Detection abilities, Cardiocondyla ants

\section{Background}

Male age is an important predictor for engagement and success in male fighting [1]. Middle-aged males often win in male-male competition, since males gain experience with age, but also loose strength when getting older. Sexually non-active males are typically not attacked, as they have not yet developed morphological secondary sexual characters, do not display the behavioural repertoire of mature males, or do not enter mating areas [1].

\footnotetext{
* Correspondence: sylvia.cremer@ist.ac.at

'Evolution, Behaviour \& Genetics, Biology I, University of Regensburg, Regensburg D-93040, Germany

${ }^{2}$ Present address: Evolutionary Biology, IST Austria (Institute of Science and Technology Austria), Klosterneuburg A-3400, Austria
}

Male-male competition is extremely pronounced in the ant genus Cardiocondyla. Whereas mating in many ants occurs during a mating flight [2], sexuals of Cardiocondyla mate in their natal nests $[3,4]$. Intra-nest mating leads to a "seraglio situation" [5] like in several species of fig wasps and parasitoid wasps [6,7], i.e., it allows males to monopolise matings with newly emerging female sexuals. This selects for rigorous fights even among closely related males [8-10].

Cardiocondyla obscurior (Wheeler, 1929) shows a conspicuous male diphenism with winged and wingless males. The wingless ("ergatoid") males mate locally within the maternal colony and are well adapted for fighting in morphology and behaviour [4,11-15]. They patrol through the nest, grab other ergatoid males with their elongated, sickle-

\section{Biomed Central}


shaped mandibles, and mark them chemically with hindgut secretions [16]. The besmeared males are killed by workers within minutes to hours, so that only a single adult ergatoid male is present per colony, even though many more may be reared [17]. Winged males, in contrast, resemble the typical ant male in morphology and behaviour: they are docile and a few days after adult emergence disperse from their natal nests [4,11-14]. Before dispersal, they may also mate with female sexuals inside the nest. Though quite vulnerable, they are normally not attacked by their wingless rivals but appear to be protected through chemical female mimicry $[18,19]$.

The different parties in male-male competition obviously have conflicting interests concerning their detectability. Dishonest female mimicry by winged males might be stable in evolution because winged males are only sporadically produced under environmental stress $[11,12]$. Winged males are thus rare compared to the constantly reared female sexuals, and it might be more costly for a wingless male to mistakenly kill a female sexual than sparing an occasional winged competitor [20]. Ergatoid males would presumably benefit from identifying other ergatoid males when these are still relatively defenseless and killing them is without risk. In contrast, young ergatoid males would increase their chance of surviving the critical first few days of their adult life by hiding their identity.

We therefore investigated how long young males are vulnerable and how early adult males can detect the presence of emerging rivals in their nests, i.e., whether detection is already possible in the pupal stage before eclosion. Behavioural observations were supplemented by the analysis of surface chemicals of young males, female sexuals, and workers, and the respective pupal stages.

\section{Methods}

\section{Study organism}

Cardiocondyla obscurior is a species that is neither endangered nor protected. Ants were collected from a single unicolonial population [13] in Una, Bahia, Brazil as allowed by Brazilian authorities (permit RMX 004/02) and reared in the laboratory as described in [11]. All experiments comply with the laws of Germany and Europe. Research with ants does not require approval by an ethics committee.

\section{Male fighting}

We observed 24 fights between pairs of ergatoid males. Males were removed from their original nests and placed in a small colony containing 10-20 workers. It was previously found that the order in which males were introduced to the workers does not affect the outcome of fights (SC unpublished observation). In the encounters, one male was older than three days ("old male"), whereas the age of the younger male varied between immediately after emergence $(\mathrm{d} 0, n=10)$, one-day old ( $11, n=7)$, and two- day old $(\mathrm{d} 2, n=7)$. For each fight we determined, which male first attacked the other, how often both males bit and besmeared one another, how often the workers bit either male, which male died or was the winner of the competition, as well as the total duration of the fights. We analysed overall $3 \times 2$ contingency tables by Fisher's exact test (VassarStats). Posthoc tests were performed as Fisher's exact tests on all three pairwise $2 \times 2$ comparisons, using a Bonferroni-adjusted significance level $\alpha=0.017$. Behavioural frequencies and fight durations were analysed by non-parametric Kruskal-Wallis tests followed by allpairwise posthoc Dunn's tests (SigmaStat 2.03).

\section{Interaction of adult males with pupae}

We observed the behaviour of single ergatoid males towards pupae in an arena (diameter $4 \mathrm{~cm}$, height $0.5 \mathrm{~cm}$ ) by scan sampling (each scan taking one to several seconds [21]) every $30 \mathrm{~min}$ over a period of five hours $(n=10$ observations per male). We placed one worker pupa, one female sexual pupa, one winged and one ergatoid male pupa onto fresh filter paper in random order in different quadrants of the arena. Pupae were either unpigmented and thus a few days prior to emergence ("white pupae," $n=12$ replicates), or darkly pigmented and thus near adult eclosion ("dark pupae," $n=12$ ). Before the experiment, we determined with empty arenas (control, $n=7$ ) that the ergatoid males did not have any a priori bias for any of the quadrants. We observed for each replicate, how often the ergatoid male was in direct contact with the different pupae and how frequently it performed antennation behaviour, biting, smearing, and copulation attempts. Contact frequencies were arcsine square root transformed and subjected to ANOVA followed by all-pairwise Protected Fisher's LSD posthoc comparisons (SPSS Version 20). The occurrence of biting, smearing and copulation behaviour in interactions of the ergatoid males to the dark pupae was tested for differences in brood type by Fisher's exact test based on $4 \times 2$ contingency tables (VassarStats). Figures are based on raw data.

\section{Chemical analysis}

We determined the cuticular hydrocarbon profiles of white and dark pupae and one-day old ants of both female castes (workers, female sexuals) and both types of males (winged, ergatoid; $n=5$ replicates each) by gas chromatography (GC; Agilent 6890 N GC with flame ionization detector equipped with a HP-5 column: $30 \mathrm{~m} * 0.25 \mathrm{~mm} * 0.25 \mu \mathrm{m})$. Cuticular compounds were identified based on their retention indices and previous mass spectrometry [19]. We extracted each sample (pupae: pools of five individuals; adults: single individuals) in $10 \mu \mathrm{l}$ pentane $(5 \mathrm{~min}$ in $1.8 \mathrm{ml}$ vials with $200 \mu \mathrm{l}$ glass inserts) and injected $5 \mu \mathrm{l}$ of the extract into the GC. Initial oven temperature was $100^{\circ} \mathrm{C}$, which was increased after $2 \mathrm{~min}$ to $180^{\circ} \mathrm{C}$ at $30^{\circ} \mathrm{C} / \mathrm{min}$, and then to $210^{\circ} \mathrm{C}$ at $10^{\circ} \mathrm{C} / \mathrm{min}$, and finally to $300^{\circ} \mathrm{C}$ at $4^{\circ} \mathrm{C} / \mathrm{min}$, and kept for 
10 min (total run time: $40.17 \mathrm{~min}$ ). Peak integration was performed with the program Chem Station. Pupae overlapped with the adult profile [19] consistently, i.e., in all individuals, in only 11 peaks (see results). These were used for statistical data analysis after transformation of the standardized peak areas following [22] as $Z_{i j}=\log \left[X_{i, j} / g\left(X_{j}\right)\right]$, where $X_{i, j}=$ standardized peak area $i$ for the sample $j$ and $g$ $\left(X_{j}\right)=$ geometric mean of all peaks of the sample $j$. Transformed data were then subjected to a principal components analysis to reduce the number of factors. To determine how well the different groups were differentiated we performed a discriminant analysis with the principal components of eigenvalues $>0.8$. Squared Mahalanobis distances were subjected to sequential Bonferroni correction due to multiple comparisons between all groups in the matrix. Multivariate statistical analyses were done with Statistica 6.0 , permutation tests with the software PAST version $1.75 \mathrm{~b}$ [23].

\section{Results}

\section{Male fighting}

Fights lasted from ten minutes to 60 hours, with the duration not being significantly dependent on whether the old ergatoid males was paired with a freshly emerged (d0; median fight length, 25\%-75\% quartile range: $367 \mathrm{~min}, 89-475 \mathrm{~min})$, a one-day old (d1; $420 \mathrm{~min}, 246-$ $1104 \mathrm{~min}$ ) or a two-day old (d2; $473 \mathrm{~min}, 349-$ $1601 \mathrm{~min}$ ) opponent (Kruskal-Wallis test $H=1.54,2 \mathrm{df}$, $P=0.46)$. The characteristics and outcome of the fights, however, strongly depended on the age of the two males, with the old male generally having an advantage over rivals one-day old or younger. Old males initiated the fights more frequently when their opponent was freshly emerged (100\%, 10/10 fights) or one-day old (86\%, 6/7 fights) than when the young male was already two days old (43\%, 3/7 fights; Fisher's exact test, $P=0.013$; posthoc comparison d0-d2: $P<0.017$, d0-d1 and d1-d2 n.s.; Figure 1A). Only in the latter case, both males occasionally attacked one another at the same time (43\%, 3/7). Biting was never performed by freshly emerged males. In contrast, when an old male was paired with a one- or two-day old opponent, both the attacking and the attacked male were biting in $43 \%(3 / 7)$ and $86 \%(6 / 7)$ of the fights (Fisher's exact test, $P<0.001$; posthoc comparison d0-d2: $P<0.017, \quad \mathrm{~d} 0-\mathrm{d} 1$ and $\mathrm{d} 1-\mathrm{d} 2$ n.s.; Figure 1B). Old males always won the fight against freshly emerged and one-day old males (10/10 and 7/7, respectively) but survived in only $43 \%$ (3/7) of fights against a two-day old rival (Fisher's exact test, $P<0.007$; posthoc comparison d0-d2: $P<0.017, \mathrm{~d} 0-\mathrm{d} 1$ and $\mathrm{d} 1-\mathrm{d} 2$ n.s.; Figure $1 C$ ). Interestingly, $43 \%$ (3/7) of these latter fights led to the death of both opponents, whereas the younger male was only able to win in a single of the observed fights (14\%).

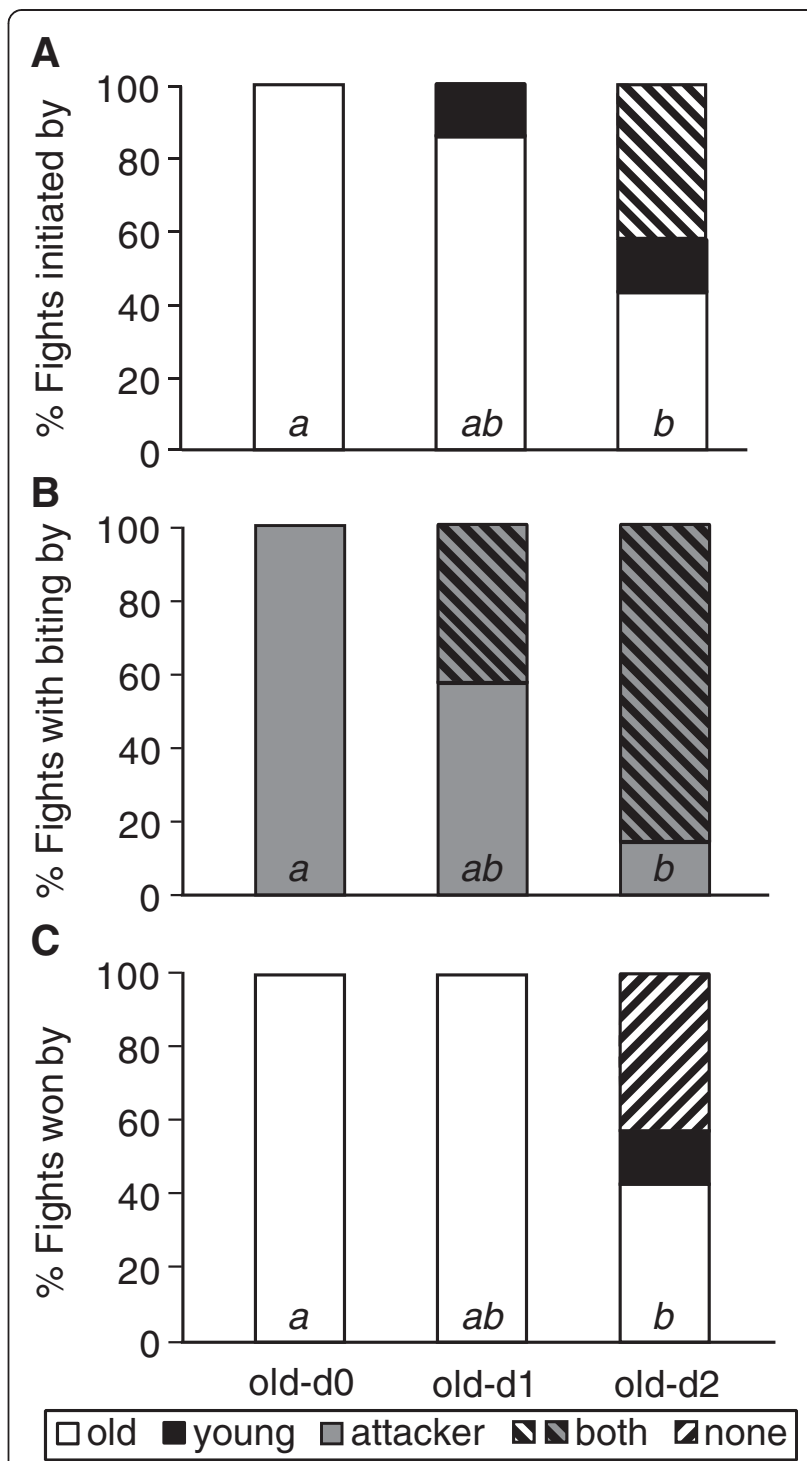

Figure 1 Fight characteristics depending on the age of ergatoid males of the ant Cardiocondyla obscurior. A) Fights were initiated more frequently by the older male when their opponent had eclosed on the day of fighting (old-d0) or was one day old (old-d1) than when the young male was two days old (oldd2). B) Biting was performed only by the attacking male when the opponent was less than one day old (old-d0), whereas both males attacked when the young male was older (old-d1 and old-d2). C) Fights were won exclusively by the older male when the rival was younger than two days (old-d0 and old-d1), yet in interactions between an old and a two-day old male, both males had similar chances of winning. Some fights resulted in the death of both males. Small italic letters indicate significance groups of the white/ grey bars.

In addition to biting, males besmeared their rivals with secretions from the anus, which elicited worker aggression. The frequency with which the later winner of the fight besmeared its rival was independent of male age $(H=1.89$, 
2df, $P=0.4$; Figure 2A). In contrast, the prospective loser besmeared its opponent more frequently in fights between old and two-day old males than in fights with a freshly eclosed male. In the latter case, besmearing did never occur $(H=12.0,2 \mathrm{df}, \quad P=0.002$; Dunn's posthoc test $\mathrm{d} 0-\mathrm{d} 2$ : $P<0.05 ; \mathrm{d} 0-\mathrm{d} 1$ and $\mathrm{d} 1-\mathrm{d} 2$ n.s.; Figure 2A). Worker attacks against the later loser did not differ between the three groups $(H=1.85,2 \mathrm{df}, P=0.49$; Figure $2 \mathrm{~B})$, but were performed at higher frequencies against the later winner in encounters of an old with a two-day old male than with a freshly emerged male $(H=11.52$, 2df, $P=0.003$; Dunn's posthoc test $\mathrm{d} 0-\mathrm{d} 2: \quad P<0.05 ; \mathrm{d} 0-\mathrm{d} 1$ and $\mathrm{d} 1-\mathrm{d} 2$ n.s.; Figure 2B). Fights between old and one-day old males showed intermediate frequencies of besmearing performed by the later loser and worker attacks towards the later winner.

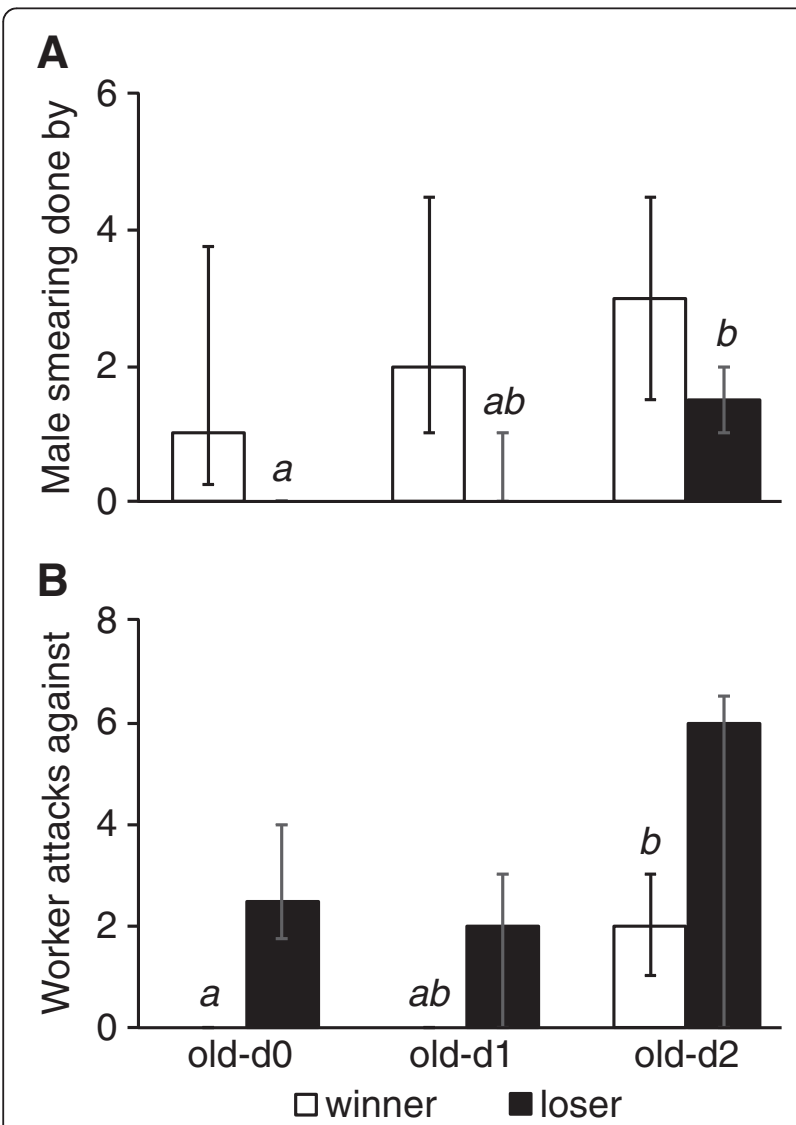

Figure 2 Male smearing and worker attacks in male-male fights of the ant Cardiocondyla obscurior. A) The frequency of observed male smearing performed by the later winner of the fight was independent of the age of the two males. Besmearing activity by the later loser increased with the age of the young male. B) Worker attacks towards the later loser of the fight did not vary with the age of the two opponents. The occurrence of worker biting against the later winner of the fight increased with the age of the young male. Bars represent median values and whiskers the 25\% and $75 \%$ quartiles. Small italic letters indicate significance groups for significant overall differences (black bars in A and white bars in B).

\section{Interaction of adult males with pupae}

Ergatoid males showed similar contact rates to all young (white) pupae of the different types (worker, female sexual, winged and ergatoid male; ANOVA $F_{3,44}=0.22, P=0.88$; Figure $3 \mathrm{~A}$ ). Yet, when pupae were close to emergence (dark pupae), female sexual and winged male pupae were contacted at higher frequencies than workers and ergatoid males (ANOVA $F_{3,44}=3.94, P=0.01$; all pairwise posthoc comparisons by Protected Fisher's LSD, $P<0.05$ for comparisons worker-female sexual, female sexual-ergatoid male, winged male-ergatoid male; Figure 3B). Moreover, ergatoid males in rare cases performed behaviours to dark pupae shortly before emergence, which are expressed regularly against the respective adults, i.e., copulation behaviour towards both female sexuals and winged males [4,14,18,24], and biting and smearing towards ergatoid males ([4,14]; Figure 4). Due to their low frequency of occurrence, these events did not significantly differ between the different types of pupae (Fisher's exact test; copulation: $P=0.60$; biting: $P=0.17$; smearing: $P=0.60)$. Copulation behaviour was observed towards one female sexual pupa $(8 \%, 1 / 12$ replicates) and two winged male pupae (17\%, 2/12). Biting was

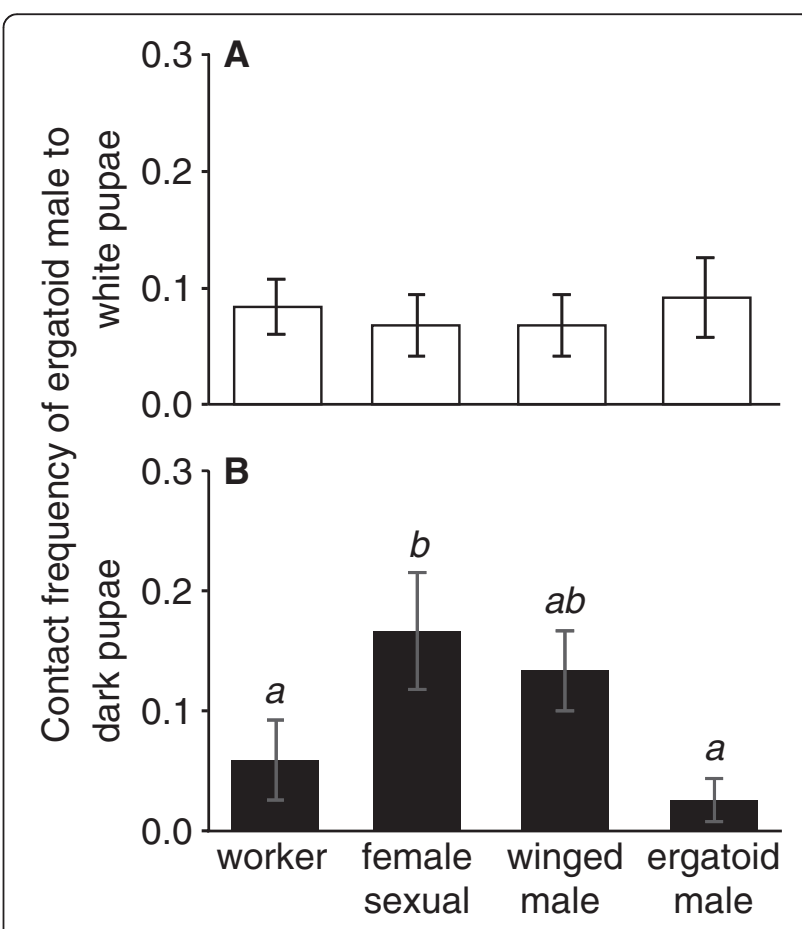

Figure 3 Contact of adult ergatoid males towards pupae of all colony members in the ant Cardiocondyla obscurior. A) Ergatoid males did not preferentially contact any type of pupae when all pupae where white and thus several days prior to emergence. B) Dark, ready-to-eclose pupae of workers and ergatoid males were contacted less frequently than female sexual pupae, as well as winged male pupae. Bars represent mean values and whiskers the standard error of the mean. Small italic letters indicate significance groups for the dark pupae that showed significant overall differences. 


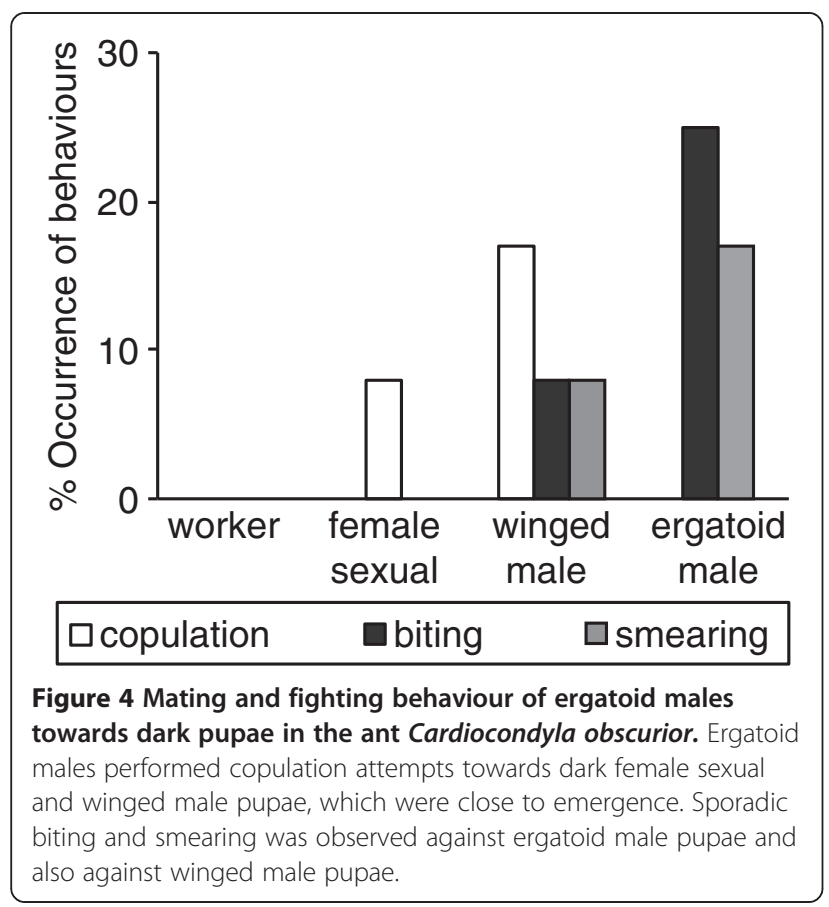

expressed towards $25 \%$ of ergatoid male pupae (3/12) and smearing towards $17 \%(2 / 12)$. Moreover, biting and smearing were observed towards one still white ergatoid male pupa. In addition, one dark winged male pupae was bitten and another one was besmeared by the ergatoid male (total $17 \%, 2 / 12$, dark winged male pupae being attacked). In contrast to fights between adult ergatoid males, however, biting of pupae did not result in a permanent grab. Instead, the pupae were immediately dropped.

\section{Chemical analysis}

Gas chromatography of cuticular hydrocarbons revealed that pupae and adults consistently shared only eleven peaks $\left(\mathrm{C}_{25} ; 11-\mathrm{meC}_{25} ; 3-\mathrm{meC}_{25} ; \mathrm{C}_{27} ; 13-, 11-\right.$, 9-meC $\mathrm{m}_{27}$; $\mathrm{C}_{29: 1} ; \mathrm{C}_{29} ; 15-, 13-, 11-\mathrm{meC}_{29} ; 7-\mathrm{meC}_{29} ; \mathrm{C}_{31: 1} ; 15-, 13-, 11-$ $\left.\mathrm{meC}_{31}\right)$. Principal components analysis of transformed and standardized peak areas resulted in two principal components with eigenvalues larger than 0.8 , which together accounted for $90.6 \%$ of the variance. Discriminant analysis with these two principal components indicated a significant separation of the 12 different groups (white pupae, dark pupae, $1 \mathrm{~d}$ old adults each of workers, female sexuals, winged males, and ergatoid males; Wilks' $\lambda=0.0127$, $\left.F_{22,94}=33.616, P<0.0001\right)$. The cuticular profiles of pupae and adults were clearly separate (Figure 5), and the squared Mahalanobis distances between white pupae and the group centroids of the corresponding adults were larger than those between dark pupae and adults (permutation t-tests; workers: $P=0.003$, female sexuals: $P<0.002$, winged males, $P=0.064$, ergatoid males: $P=0.053$ ). Most misclassifications occurred between different types of

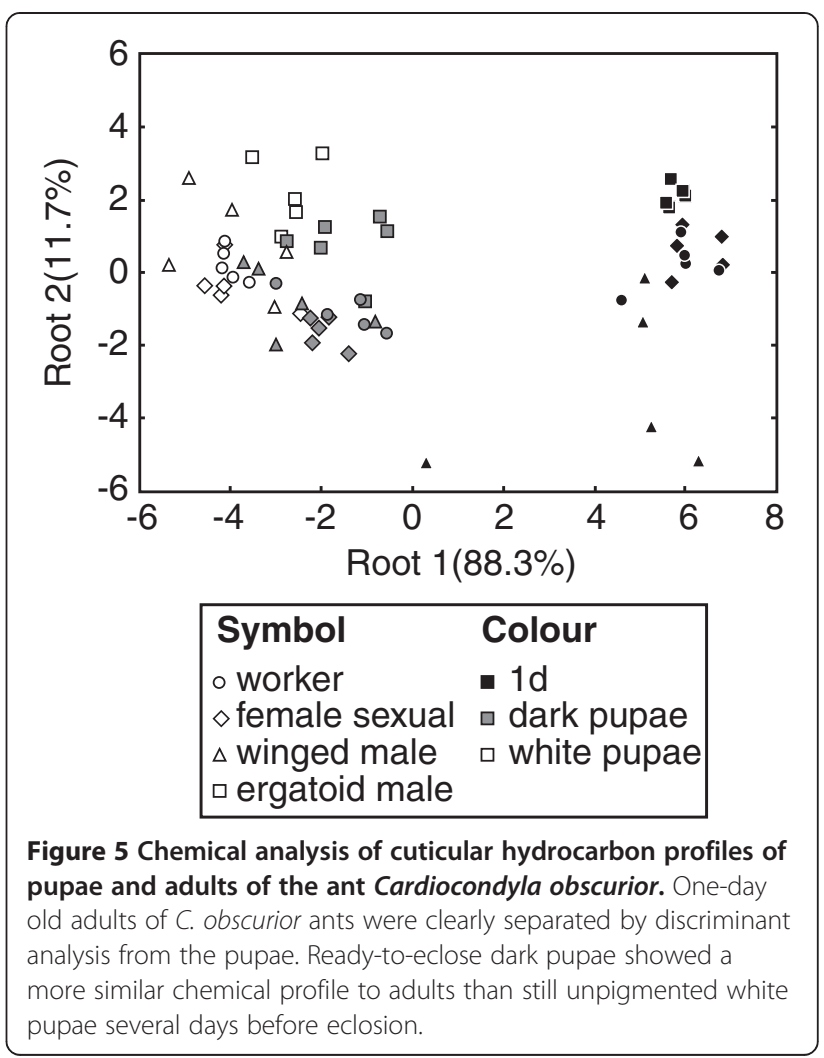

pupae or between different types of adults and only a single adult was incorrectly classified as a pupa (a one-day old winged male as a dark female sexual pupa). Over all life stages, correct classifications occurred in $60 \%$ of the cases. Most female sexuals and ergatoid males were correctly classified, which matches the behavioural observations. Misclassifications occurred at similar frequencies among white pupae (9/20), dark pupae (8/20) and adults (7/20). Most squared Mahalanobis distances between ant types of the same age group were no longer significant after sequential Bonferroni correction. Exceptions involved adult winged males, which were separate from all other adults, dark ergatoid male pupae, which were different from dark female sexual pupae, and white ergatoid male pupae, which differed from white pupae of female sexuals and workers.

\section{Discussion}

Our study shows that ergatoid males benefit from attacking emerging ergatoid rivals as soon as possible after eclosion, even if the latter do not yet engage in sexual activities. Older males consistently won fights against males of an age of one day or less, whereas they only survived $43 \%$ of the fights against two-day old opponents (Figure 1). Very young males hardly showed any fighting behaviour themselves (Figure 2). Their cuticula is not yet fully sclerotized and does not provide any protection 
against bites by older individuals (SC and AS, unpublished observation). Furthermore, the softness of their mandibles does not allow freshly emerged males to attack others. In contrast, two-day old ergatoid males were similarly active as older males and equally likely to initiate or win a fight. Encounters among older males led to pronounced fighting, in which occasionally both males were killed. By attacking freshly emerged ergatoid males, adult ergatoids therefore remove future competitors at the lowest possible risk. Old males that are unable to quickly detect an emerging rival male have a $>50 \%$ chance of being killed and replaced by a younger male.

Earlier eclosing males appear to have a competitive advantage over those that eclose later also in other species with fatal fighting and local mate competition (LMC), e.g., parasitoid wasps $[6,25]$. In addition, differences in body size and previous fighting experience may affect the outcome of fights in parasitoids [25] and several insects without LMC [26-29]. However, these two factors appear to be much less important in fights between ergatoid males of C. obscurior than the timing of emergence (AS and SC, unpublished data).

Obviously, the advantage of early emergence results in a conflict of interest over the timing of the detectability of ergatoid males. On the one hand, it pays for an adult ergatoid to recognize and remove competitors as early as possible, as eliminating pupae is presumably even safer than killing freshly emerged ergatoids. On the other hand, young ergatoid males would benefit by concealing their identity until their cuticula is sclerotized and they have a reasonable chance of surviving a confrontation with an older male. Ergatoid males almost incessantly patrol through the nest and examine the brood pile for freshly eclosed ergatoids and young female sexuals [30,31]. Our behavioural analysis revealed that ergatoid males did not differentiate between the different types of unpigmented pupae several days prior to emergence, but showed increased contact to close-to emergence (dark) female sexual and winged male pupae (Figure 3). Also, whereas ergatoid males only showed antennation (i.e. detection [32]) behaviour towards young, unpigmented pupae several days before emergence, they were occasionally seen attempting to mate with female sexual and winged male pupae and attacking ergatoid male and also winged male pupae (Figure 4). Attacks against pupae were weak compared to encounters between adults and more intense behavioural observations will be required to determine how frequently these interactions occur and whether workers may kill besmeared ergatoid male pupae. Nevertheless, it appears that the conflict of interest has been decided in favour of the adult ergatoids.

The observed differences in ergatoid male behaviour towards unpigmented early pupae and dark pupae shortly before emergence may be based on their chemical signatures. We found that the cuticular hydrocarbon profiles of dark, ready-to-eclose pupae were more similar to those of adults than the profiles of white pupae (Figure 5). The chemical profile of dark pupae might therefore allow ergatoid males to determine the destiny of the emerging ant with at least some accuracy. Still, differences in the chemical profiles between ant types are likely not large enough to allow faultless determination. The costs of misidentifying and inadvertently killing a female sexual or worker pupa might explain why ergatoid males of $C$. obscurior did not kill ergatoid male pupae. This may be additionally pronounced by the fact that the chemical signal of pupae was also quantitatively less intense than that of adults: for GC analyses, we had to pool five pupae to obtain similar quantities of cuticular hydrocarbons as from single adults.

It has been shown previously that winged males of $C$. obscurior perform a chemical female mimicry that protects them against attacks of ergatoid males in the early days after emergence before they leave the colony [18]. Moreover, they adjust the timing of dispersal from the nest both to the availability of mating partners in the nest and the presence of ergatoid fighter males [33]. This might suggest that winged males may become a target for ergatoid male aggression once their chemical similarity to female sexuals fades [33]. In the present study, we found some indication that ergatoid males can already be lured to attempt copulation with dark winged male pupae prior to emergence. Whereas adult C. obscurior ants are characterised by a large set of 44 cuticular hydrocarbons [19], only 11 peaks overlapped between the pupal and adult profiles and were thus analysed in the current study. A comparison between the one-day old adults of the current study revealed that these shared 11 peaks are not identical with those peaks thought to be responsible for the chemical female mimicry $[18,19]$.

\section{Conclusion}

Though young ergatoid males would obviously benefit from concealing their identity they fail to do so. Whereas winged males perform successful female mimicry [18], ergatoid males may be morphologically too different from female sexuals (in size and the absence of wings) to allow successful female mimicry. The observed absence of selfconcealment by young ergatoid males may be selected at the colony level rather than the individual level. In $C$. obscurior, female sexuals and ergatoid males are produced throughout the year and mating occurs in the natal nest. The colony as a whole might benefit from producing replacement ergatoids ready to mate with the continuously emerging young female sexuals in case the old ergatoid male dies. The cost of uninseminated female sexuals lies in a reduced colony growth due to a very low lifetime reproductive output of virgins. Even if uninseminated females can contribute to colony reproduction by laying unfertilised, male destined eggs, both their egg laying rate 
and lifespan are much below that of mated queens [34], whereas the latter even increase their egg laying efficiency with age [35]. In comparison to the loss of future colony growth through insufficient mating opportunities for female sexuals the costs of producing surplus ergatoid males might be relatively small. Furthermore, investment in surplus ergatoids is not completely lost as killed ergatoids are quickly 'recycled', i.e. dismembered, and fed to the larvae [36].

Despite their distinct chemical profile, ergatoid males may occasionally remain undetected because a) they are quite inactive during the first hours after eclosion, b) colonies may be so large that the resident male cannot fully control all brood piles, and c) queens produce so many males that not all are eliminated by the old male. LMC in single-queened nests of $C$. obscurior leads to the production of only very few new ergatoid males, while many more ergatoids are produced when multiple queens reproduce in the same nest $[17,37]$. We have previously argued that queens in multi-queen societies in this way may increase their chances of one of their own sons winning male-male competition [17]. The current study suggests that the presence of multiple pupae or freshly emerged ergatoid males might distract the resident male and thus increase the chance of individual queens that their own sons reach a well-fortified age undetected.

\section{Competing interests}

The authors declare no competing interests.

\section{Authors' contributions}

SC and $\mathrm{JH}$ designed the study. SC and AS performed the behavioural observations and MS the gas chromatography analyses. SC analysed the behavioural data and $\mathrm{JH}$ the chemical data. SC, AS and $\mathrm{JH}$ wrote the paper. All authors read and approved the final manuscript.

\section{Acknowledgements}

We thank Martin Waldherr and Birgit Lautenschläger for help in the experiments, Falko Drijfhout for help with chemical analysis, and Line V. Ugelvig for help with figure preparation. The study was funded by Deutsche Forschungsgemeinschaft (He 1623/23). The funding body had no role in design, collection, analysis and interpretation of the data, in the writing of the manuscript and in the decision to submit the manuscript for publication.

Received: 24 February 2012 Accepted: 21 May 2012

Published: 15 June 2012

\section{References}

1. Andersson M: Sexual Selection. Princeton, NJ: Princeton University Press; 1994.

2. Hölldobler B, Bartz SH: Sociobiology of reproduction in ants. In Experimental Behavioral Ecology and Sociobiology. Edited by Hölldobler B, Lindauer M. New York: Academic; 1985:167-220.

3. Heinze J, Cremer S, Eckl N, Schrempf A: Stealthy invaders: the biology of Cardiocondyla tramp ants. Insect Soc 2006, 53:1-7.

4. Kinomura K, Yamauchi K: Fighting and mating behaviors of dimorphic males in the ant Cardiocondyla wroughtoni. J Ethol 1987, 5:75-81.

5. Hamilton WD: Evolution and diversity under bark. In Diversity of insect faunas. Edited by Mound LA, Waloff N. Oxford: Blackwell Scientific; 1978:154-175.

6. Abe J, Kamimura Y, Shimada M: Individual sex ratios and offspring emergence patterns in a parasitoid wasp, Melittobia australica
(Eulophidae), with superparasitism and lethal combat among sons. Behav Ecol Sociobiol 2005, 57:366-373.

7. West SA, Murray MG, Machado CA, Griffin AS, Herre EA: Testing Hamilton's rule with competition between relatives. Nature 2001, 409:510-513.

8. West SA, Pen I, Griffin AS: Cooperation and competition between relatives. Science 2002, 296:72-75.

9. Anderson C, Cremer S, Heinze J: Live and let die: why fighter males of the ant Cardiocondyla kill each other but tolerate their winged rivals. Behav Ecol 2003, 14:54-62.

10. Frank SA: Foundations of Social Evolution. Princeton: Princeton University Press; 1998.

11. Cremer S, Heinze J: Stress grows wings: environmental induction of winged dispersal males in Cardiocondyla ants. Curr Biol 2003, 13:219-223.

12. Du Y, Schrempf A, Heinze J: Environmental determination of the male morph in the ant Cardiocondyla obscurior (Hymenoptera: Formicidae) Eur J Entomol 2007, 104:243-246.

13. Heinze J, Delabie JHC: Population structure of the male-polymorphic ant Cardiocondyla obscurior. Stud Neotrop Fauna Environ 2005, 40:187-190.

14. Stuart RJ, Francoeur A, Loiselle R: Lethal fighting among dimorphic males of the ant, Cardiocondyla wroughtonii. Naturwissenschaften 1987, 74:548-549.

15. Kugler J: The males of Cardiocondyla emery (Hymenoptera: Formicidae) with the description of the winged male of Cardiocondyla wroughtoni (Forel). Isr J Entomol 1983, 17:1-21.

16. Yamauchi K, Kawase N: Pheromonal manipulation of workers by a fighting male to kill his rival males in the ant Cardiocondyla wroughtonii. Naturwissenschaften 1992, 79:274-276.

17. Cremer S, Heinze J: Adaptive production of fighter males: queens of the ant Cardiocondyla adjust the sex ratio under local mate competition. Proc R Soc Lond B 2002, 269:417-422.

18. Cremer $S$, Sledge MF, Heinze J: Male ants disguised by the queen's bouquet. Nature 2002, 419:897.

19. Cremer S, d'Ettorre P, Drijfhout FP, Sledge MF, Turillazzi S, Heinze J: Imperfect chemical female mimicry in males of the ant Cardiocondyla obscurior. Naturwissenschaften 2008, 95:1101-1105.

20. Heinze J, d'Ettorre P: Honest and dishonest communication in social Hymenoptera. J Exp Biol 2009, 212:1775-1779.

21. Martin P, Bateson P: Measuring Behaviour. An Introductory Guide. 2nd edition. Newcastle: Cambridge University Press; 1993.

22. Reyment RA: Compositional data analysis. Terra Rev 1989, 1:29-34.

23. Hammer $\varnothing$, Harper DAT, Ryan PD: PAST: Palaeontological statistics software package for education and data analysis. Palaeontol Electr 2001, 4:1.

24. Mercier J-L, Lenoir J-C, Eberhardt A, Frohschammer S, Williams C, Heinze J: Hammering, mauling, and kissing: stereotyped courtship behaviour in Cardiocondyla ants. Insectes Soc 2007, 54:403-411.

25. Innocent TM, Savage J, West SA, Reece SE: Lethal combat and sex ratio evolution in a parasitoid wasp. Behav Ecol 2007, 18:709-715.

26. Reaney LT, Drayton JM, Jennions MD: The role of body size and fighting experience in predicting contest behaviour in the black field cricket, Teleogryllus commodus. Behav Ecol 2011, 65:217-225.

27. Goldsmith SK, Stewart Z, Adams S, Trimble A: Body size, male aggression, and male mating success in the cottonwood borer, Plectrodera scalator (Coleoptera, Cerambycidae). J Ins Behav 1996, 9:719-727.

28. Hanks LM, Millar JG, Paine TD: Body size influences mating success of the eucalyptus longhorned borer (Coleoptera, Cerambycidae). J Ins Behav 1996, 9:369-382.

29. Alcock J: The relation between male body size, fighting, and mating success in Dawson's burrowing bee, Amegilla dawsoni (Apidae, Apinae, Anthoporini). J Zool 1996, 239:663-674.

30. Heinze J, Hölldobler B: Fighting for a harem of queens: physiology and reproduction in Cardiocondyla male ants. Proc Natl Acad Sci USA 1993, 90:8412-8414.

31. Heinze J, Kühnholz S, Schilder K, Hölldobler B: Behaviour of ergatoid males in the ant, Cardiocondyla nuda. Insectes Soc 1993, 40:273-282.

32. Vander Meer RK, Morel L: Nestmate recognition in ants. In Pheromone Communication in Social Insects. Edited by Winston ML. Boulder, Colorado: Westview Press; 1998:79.

33. Cremer S, Schrempf A, Heinze J: Competition and opportunity shape the reproductive tactics of males in the ant Cardiocondyla obscurior. PLOS One 2011, 6:e17323.

34. Schrempf A, Heinze J, Cremer S: Sexual cooperation: mating increases longevity in ant queens. Curr Biol 2005, 15:267-270. 
35. Heinze J, Schrempf A: Terminal investment: individual reproduction of ant queens increases with age. PLoS One 2012, 7:e35201.

36. Schrempf A, Heinze J: Proximate mechanisms of male morph determination in the ant Cardiocondyla obscurior. Evol Dev 2006, 8:266-272.

37. de Menten L, Cremer S, Heinze J, Aron S: Primary sex ratio adjustment by ant queens in response to local mate competition. Anim Behav 2005, 69:1031-1035.

doi:10.1186/1472-6785-12-7

Cite this article as: Cremer et al:: The dynamics of male-male competition in Cardiocondyla obscurior ants. BMC Ecology 2012 12:7.

\section{Submit your next manuscript to BioMed Central} and take full advantage of:

- Convenient online submission

- Thorough peer review

- No space constraints or color figure charges

- Immediate publication on acceptance

- Inclusion in PubMed, CAS, Scopus and Google Scholar

- Research which is freely available for redistribution 